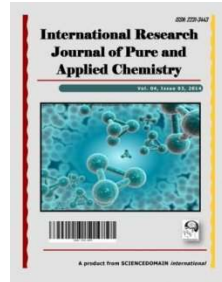

International Research Journal of Pure \& Applied Chemistry

13(1): 1-9, 2016; Article no.IRJPAC.30222

ISSN: 2231-3443, NLM ID: 101647669

SCIENCEDOMAIN international

www.sciencedomain.org

\title{
A Theoretical Study of 2-nitrofuran vs 3-nitrofuran as Dienophilic Electrophile in Polar Cycloaddition Reaction: Comparison of the Reactivity and Reaction Mechanism
}

\author{
Mauro Cainelli ${ }^{1}$, Carla M. Ormachea ${ }^{1}$, Pedro M. E. Mancini ${ }^{1}$ \\ and María N. Kneeteman ${ }^{1^{*}}$ \\ ${ }^{1}$ Laboratorio Fester, Química Orgánica, IQAL (UNL-CONICET), Facultad de Ingeniería Química, \\ Santa Fe, Argentina.
}

Authors' contributions

This work was carried out in collaboration between four authors. Authors CMO and MC realized the theoretical calculations which appear in this study. Authors MNK and PMEM wrote the protocol and preformed the global analysis related to the Polar Diels-Alder reactions. All authors participated in the analysis of the solvent effect in this type of reactions. Authors MNK and PMEM read and approved the

final manuscript.

Article Information

DOI: 10.9734/IRJPAC/2016/30222

Editor(s):

(1) Li Cai, Department of Chemistry, University of South Carolina Salkehatchie, USA.

Reviewers:

(1) V. Kannan, University in Kattappana, India. (2) Nadia Sabry El-Gohary, Mansoura University, Egypt.

(3) Ricci Alfredo, Bologna University, Italy.

Complete Peer review History: http://www.sciencedomain.org/review-history/17020

Original Research Article

Received $25^{\text {th }}$ October 2016 Accepted $18^{\text {th }}$ November 2016 Published 24 ${ }^{\text {th }}$ November 2016

\section{ABSTRACT}

In this study, we analyzed in a theoretical form the behavior of 2-nitrofuran and 3-nitrofuran acting as dienophilic electrophiles in polar cycloaddition reactions joint to different dienes. The reactivity and regioselectivity was discussed employing global and local reactivity indexes, respectively The reaction mechanisms of these cycloadditions were compared through the transition state structures and energies calculated.

${ }^{*}$ Corresponding author: E-mail: mkneeteman@fiq.unl.edu.ar; 
Keywords: 2-nitrofuran; DFT; mechanism; cycloaddition reaction.

\section{INTRODUCTION}

The Diels-Alder (DA) reaction is a powerful and useful tool in synthetic organic chemistry that allows the construction of a six-membered ring in one step. The process involves the formation of two $\sigma$ bounds and the rupture of two $\pi$ bounds simultaneously between a compound with two conjugated double bonds (diene) and a compound with one double bond (dienophile), producing regioselective and stereoespecific products $[1,2]$.

A wide variety of dienes and dienophiles can be used. Previous studies demonstrated that aromatic heterocycles can act as dienophiles in DA reactions [3] when these compounds are properly substituted with electron withdrawing groups such as carbonyl and nitro group [4].

According to the Frontier Molecular Orbital (FMO) theory, in this reaction the bonding formations involve a charge transfer (CT) process between the Highest Occupied Molecular Orbital (HOMO) and the Lowest Unoccupied Molecular Orbital (LUMO) of the reactants [5]. The properly employment of substituents in both, diene and dienophile, decrease the energy gap between these orbitals, resulting in a more favored reactive process [6-7].

The mechanisms of these reactions can be considered, normally, as a concerted synchronous or asynchronous process. In the synchronous process, the rate of rupture and formation of the bonds in the transition state (TS) are the same and the reaction is non-polar, while in the asynchronous process the rates are different and the reaction is known as Polar Diels-Alder reaction (P-DA) [8-10]. The first mechanism is observed when the bonding atoms have similar reactivity, for example when the diene and the dienophile are symmetric, while the second one is observed when the polarities are different, which is the most common situation. A theoretical study, based on the Density Functional Theory (DFT) methods, of the behavior of dienes and dienophiles in DA reactions allows explaining the feasibility of the cycloaddition processes and the type of mechanism observed in each one [11].

Recently a theoretical study was developed to analyze the reaction mechanism of 3-nitrofuran acting as electrophilic dienophile in P-DA reactions with different dienes. It has been demonstrated that 3-nitrofuran reacts efficiently with the selected dienes in normal electron demand P-DA reactions, with the nitro group inducing the formation of a selective product [12]. In this work, we analyze the mechanism of the reaction between 2-nitrofuranand the dienes. Then, we compare the reactivity and reaction mechanisms with those observed in 3-nitrofuran reactions.

\section{COMPUTATIONAL METHODS}

The theoretical DFT calculations were carried out using the Gaussian 09 [13] program. The hybrid functional method [14] employed was B3LYP [15], together with the standard $6-31 \mathrm{G}(\mathrm{d})$ basis set [16].

Geometric structures of reactants and products were optimized using the Berny analytical gradient optimization method [17]. The mechanistic study was realized through the construction of the Potential Energy Surface (PES) for every system. The structures of transition states (TSs) were located, optimized and then verified through IRC (Intrinsic Reaction Coordinates) calculations [18]. The frequency calculations were done to validate the optimized structures. Reactants and cycloadduct (CA) structures were verified by the absence of negative frequencies, and the TSs by the presence of only one imaginary frequency that corresponds to the bond formation.

The reactivity of the systems was studied using some indexes defined in terms of the electronic chemical potential $(\mu)$ and the chemical hardness

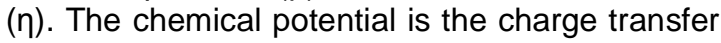
capacity of the system in basal state and the hardness is the resistance to change the chemical potential when the number of electrons variates. Both quantities may be approached in terms of the one electron energies of the frontier molecular orbital HOMO and LUMO, $\varepsilon \mathrm{H}$ and $\varepsilon \mathrm{L}$ [19].

$$
\begin{gathered}
\mu=\frac{\varepsilon_{H}+\varepsilon_{L}}{2} \\
\eta=\varepsilon_{L}-\varepsilon_{H}
\end{gathered}
$$

The global electrophilicity index, $\omega$, represents the capability of a molecule to accept an electron 
considering the environment satured by them and it's given by the following simple expression.

$$
\omega=\frac{\mu^{2}}{2 \eta}
$$

Recently an empirical (relative) nucleophilicity index, $N$, has been introduced based on the HOMO energies obtained within the Kohn-Sham scheme.

$$
N=\varepsilon_{\text {Номо }(N u)}-\varepsilon_{\text {Номо }(T C E)}
$$

The nucleophilicity is referred to tetracyanoethylene (TCE), which presents the lowest $\mathrm{HOMO}$ energy in relation to large series of molecules already investigated in the context of polar cycloadditions [20].

Fukui function is a measure of the sensibility of the chemical potential in a particular point when an external perturbation is present and the number of electrons remain constant, or the variation of the electronic density in a point when the number of electron changes and the external potential remains constant [21].

$$
f(r)=\left(\frac{\partial \rho(r)}{\partial n}\right)_{v(r)}=\left(\frac{\partial \mu}{\partial v(r)}\right)_{n}
$$

The resolution of this function can be obtained in terms of the FMO.

$$
\begin{aligned}
& f_{k}^{\alpha}=\sum_{\mu \in k} f_{\mu}^{\alpha} \\
& f_{\mu}^{\alpha}=\left|c_{\mu \alpha}\right|^{2}+c_{\mu \alpha} \sum_{v \neq \mu} c_{v \alpha} S_{\mu v}
\end{aligned}
$$

$f_{k}^{+}$and $f_{k}^{-}$are the Fukui functions for a nucleophilic and electrophilic attack, respectively. Local electrophilicity and nucleophilicity indexes, $\omega k$ and $N k$, can be obtained using the following expressions

$$
\omega_{k}=\omega f_{k}^{+}
$$

$$
N_{k}=N f_{k}^{-}
$$

The optimization structures provide the values of HOMO and LUMO orbitals that are used to quantify the reactivity indexes [22].

\section{RESULTS AND DISCUSSION}

\subsection{Global Properties of Dienophile and Diene}

In order to compare the reactivity of 2-nitrofuran (Fig. 1) with 3-nitrofuran, the global properties were calculated (Table 1).

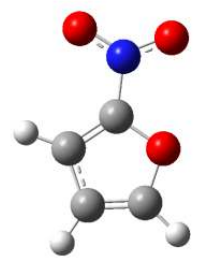

\section{Fig. 1. Structure of 2-nitrofuran}

The global electrophilicity $(\omega)$ of 2-nitrofuranis $2.51 \mathrm{eV}$ which is a little higher than in case of 3nitrofuran $(2.35 \mathrm{eV})$.

The dienes used in this study are 2-methyl-1,3butadiene (Isoprene) (1), 1-methoxy-1,3butadiene (2) and 1-methoxy-3-trimethylsilyloxy1,3-butadiene (Danishefsky's diene) (3) (Scheme 1 ). The reactivity is analyzed comparing the differences of global electrophilicity between the dienophile and the different dienes (Table 2).

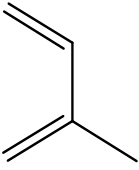

1

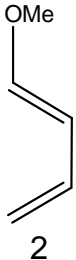

2

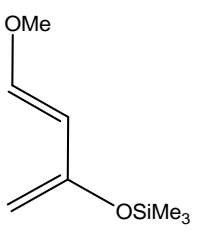

3
Scheme 1. Structure of dienes

Table 1. Electronic properties of 2-nitrofuran

\begin{tabular}{lllllll}
\hline Dienophile & $\varepsilon_{\text {HоMо }}(\mathrm{eV})$ & $\varepsilon_{\text {LUMO }}(\mathrm{eV})$ & $\mu(\mathrm{eV})$ & $\boldsymbol{\eta}(\mathrm{eV})$ & $\omega(\mathrm{eV})$ & $\boldsymbol{N}(\mathrm{eV})$ \\
\hline 2-nitrofuran & -0.26971 & -0.09222 & -0.180965 & 0.17749 & $\mathbf{2 . 5 1}$ & $\mathbf{1 . 7 8}$ \\
\hline
\end{tabular}

Table 2. Electronic properties of dienes

\begin{tabular}{lllllll}
\hline Diene & $\boldsymbol{\varepsilon}_{\text {HOMO }}(\mathrm{eV})$ & $\boldsymbol{\varepsilon}_{\text {LUMO }}(\mathrm{eV})$ & $\boldsymbol{\mu}(\mathrm{eV})$ & $\boldsymbol{\eta}(\mathrm{eV})$ & $\boldsymbol{\omega}(\mathrm{eV})$ & $\boldsymbol{N}(\mathrm{eV})$ \\
\hline Isoprene & -6.18 & -0.41 & -3.30 & 5.77 & $\mathbf{0 . 9 4}$ & $\mathbf{2 . 9 3}$ \\
1-methoxy-1,3-butadiene & -5.57 & -0.14 & -2.85 & 5.43 & $\mathbf{0 . 7 5}$ & $\mathbf{3 . 5 5}$ \\
Danishefsky's diene & -5.56 & 0.04 & -2.76 & 5.60 & $\mathbf{0 . 6 8}$ & $\mathbf{3 . 5 6}$ \\
\hline
\end{tabular}


This difference $(\Delta \omega)$ presents the highest value for Danishefsky's diene (2) $(\omega=0.96 \mathrm{eV})$. Then the reactions involving this diene would be more favourable than those in which 1-methoxy-1,3butadiene (3) $(\omega=1.07 \mathrm{eV})$ or isoprene (4) ( $\omega$ $=1.27 \mathrm{eV}$ ) are employed.

\subsection{Local Properties of Dienophile and Diene}

The regioselectivity was analyzed using the local properties of the dienophile (Table 3 ) and dienes (Table 4).

Table 3. Local electrophilicity of 2-nitrofuran

\begin{tabular}{lll}
\hline Dienophile & & $\boldsymbol{\omega}_{\mathbf{k}}(\mathrm{eV})$ \\
\hline 2-nitrofuran & $\mathrm{C}_{2}$ & $\mathbf{0 . 1 0}$ \\
\cline { 2 - 3 } & $\mathrm{C}_{3}$ & $\mathbf{0 . 3 8}$ \\
\hline
\end{tabular}

In case of 2-nitrofuran, the local electrophilicity of $\mathrm{C}_{2}$ and $\mathrm{C}_{3}$ are $0.10 \mathrm{eV}$ and $0.38 \mathrm{eV}$ respectively $\left(\Delta \omega_{k}=0.28 \mathrm{eV}\right)$, while for 3-nitrofuran are 0.43 $\mathrm{eV}$ and $0.06 \mathrm{eV}$ respectively $\left(\Delta \omega_{\mathrm{k}}=0.37 \mathrm{eV}\right)$. It's observed that the most electrophilic center is, in both cases, the carbon atom next to the one substituted with the nitro group.

Table 4. Local electrophilicity of dienes

\begin{tabular}{lll}
\hline Diene & & $N_{\mathbf{k}}(\mathbf{e V})$ \\
\hline Isoprene & $\mathrm{C}_{1}$ & $\mathbf{1 . 2 0}$ \\
\cline { 2 - 3 } & $\mathrm{C}_{4}$ & $\mathbf{0 . 9 2}$ \\
\hline 1-metoxy-1,3-butadiene & $\mathrm{C}_{1}$ & $\mathbf{0 . 7 4}$ \\
\cline { 2 - 3 } & $\mathrm{C}_{4}$ & $\mathbf{0 . 9 4}$ \\
\hline Danishefsky's diene & $\mathrm{C}_{1}$ & $\mathbf{0 . 5 6}$ \\
\cline { 2 - 3 } & $\mathrm{C}_{4}$ & $\mathbf{1 . 4 6}$ \\
\hline
\end{tabular}

On the other hand, the dienes have a local nucleophilicity in $\mathrm{C}_{1}$ and $\mathrm{C}_{4}$ of $1.20 \mathrm{eV}$ and 0.92 $\mathrm{eV}\left(\Delta N_{k}=0.28 \mathrm{eV}\right)$ respectively for isoprene, $0.74 \mathrm{eV}$ and $0.94 \mathrm{eV}\left(\Delta N_{k}=0.20 \mathrm{eV}\right)$ respectively for 1-metoxi-1,3-butadiene, $0.56 \mathrm{eV}$ and $1.46 \mathrm{eV}$ $\left(\Delta N_{k}=0.90 \mathrm{eV}\right)$ respectively for the Danishefsky's diene. The regioselectivity is expected to be higher for the processes that involve Danishefsky's diene due to the higher difference in the local nucleophilicity between $\mathrm{C}_{1}$ and $\mathrm{C}_{4}$ which is a consequence of the electron donor groups (-OMe y-OSiMe3) and its relative positions, specially the methoxy group.

It's expected that atoms of the dienophile with higher values of local electrophilicity $\left(\mathrm{C}_{3}\right.$ in case of 2-nitrofuran) will react with the atoms with higher values of local nucleophilicity of the diene ( $\mathrm{C}_{4}$ in case of the Danishefsky's diene).

\subsection{Reaction Mechanism}

The primary adducts of the DA reactions involving nitro-dienophiles are usually not observed experimentally due to the elimination of the nitro group as nitrous acid. This is an irreversible process that involves several reactions which leads to the subsequent aromatization of the products. If asymmetric dienes such as Danishefsky's diene are used, the process involves the elimination of methoxy group and the hydrolysis of trimethylsilyloxy group.

In this study, it's analyzed the reaction mechanism of the DA process until the formation of the primary adducts because this is the determinant step of the reaction. The loose of nitro group is irreversible. This step of the process is favored by the aromatic character of the final product.

\subsubsection{2-nitrofuran + isoprene}

The $\Delta N_{k}$ between $\mathrm{C}_{1}$ and $\mathrm{C}_{4}$ is not enough to observe regioselectivity and both isomers appears products (Scheme 2). The isomers relation was dihydro/aromatic 1:3. The elimination of the nitro group allows to obtain a mixture of dihydro and aromatic isomers as final products.

The $\Delta \omega$ of the reaction for this system is $1.57 \mathrm{eV}$. This reaction presents one transition state (TS, Fig. 2) for each, para and meta products.

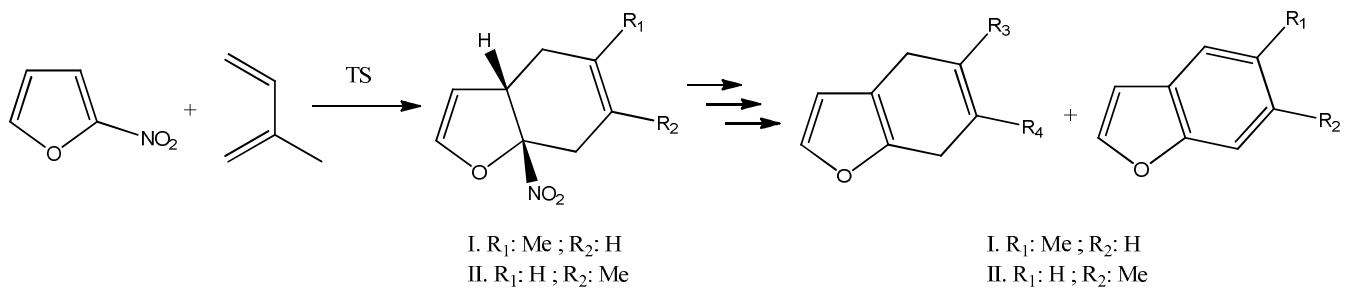

Scheme 2. Diels-Alder reaction between 2-nitrofuran and isoprene 

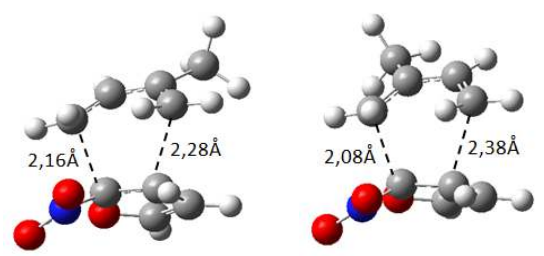

Fig. 2. Transition states for para and meta cycloadducts

This process is concerted and asynchronous because both formatting bonds vibrate at the same time and in an asymmetric form $\left[\left(\Delta \mathrm{r}_{\text {para }}=\right.\right.$ $0.12 \AA), \quad\left(\Delta r_{\text {meta }}=0.30 \AA\right.$ where $\Delta r$ is the difference in length of the forming bonds at TS. The energy barrier of both isomers is similar $(24$ $\mathrm{kcal} / \mathrm{mol}$ ) which validate the obtention of the two products (Fig. 3a). The energy barrier of this reaction is higher than that in which 3-nitrofuran is employed as dienophile $(17.5 \mathrm{kcal} / \mathrm{mol})$ (Fig. 3b).

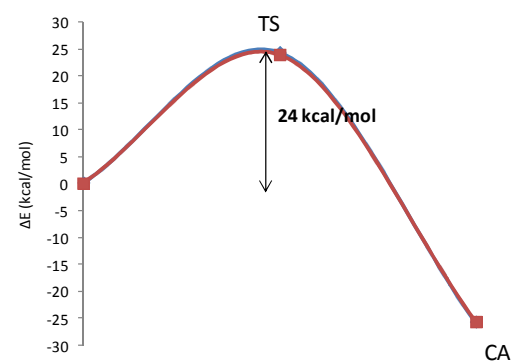

a)

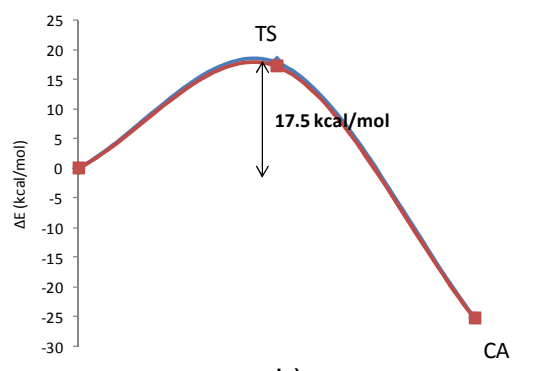

b)

Fig. 3. Reaction path of 2-nitrofuran (a) and 3nitrofuran (b) with isoprene

\subsubsection{2-nitrofuran+1-methoxy-1,3-butadiene}

In this case the methoxy group is eliminated as methanol after the cycloaddition, together with the nitro group. Both isomers reach the same aromatic product (Scheme 3).

The $\Delta \omega$ of the reaction for this system is $1.76 \mathrm{eV}$. This reaction presents one transition state (TS, Fig. 4) for each, ortho and meta products.
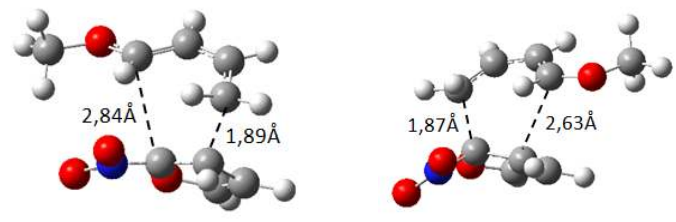

Fig. 4. Transition states for ortho and para cycloadducts

This process is concerted and asynchronous because both formatting bonds vibrate at the same time and in an asymmetric form $\left[\left(\Delta \mathrm{r}_{\text {para }}=\right.\right.$ $0.95 \AA),\left(\Delta r_{\text {meta }}=0.76 \AA\right)$. The energy barrier of the ortho isomers is $22.5 \mathrm{kcal} / \mathrm{mol}$ and the energy of the para isomer is slightly higher $\left(\Delta \mathrm{E}_{\mathrm{a}}=2.52\right.$ $\mathrm{kcal} / \mathrm{mol}$ ) (Fig. 5a). The energy barrier of the ortho cycloadduct is higher than those in which 3-nitrofuran is employed as dienophile (13.37 $\mathrm{kcal} / \mathrm{mol})$. Moreover, the energy difference between both isomers in this case is higher $\left(\Delta \mathrm{E}_{\mathrm{a}}\right.$ $=14.81 \mathrm{kcal} / \mathrm{mol}$ ) (Fig. 5b).

\subsubsection{2-nitrofuran + Danishefsky's diene}

The $\Delta N_{k}$ between $\mathrm{C}_{1}$ and $\mathrm{C}_{4}$ in this diene is high enough to observe the formation of only one isomer (Scheme 4). In this case the methoxy group is also eliminated as methanol and the trimethylsilyloxy group is hydrolyzated together with the elimination of the nitro group to reach the final hydroxylated aromatic product.

The $\Delta \omega$ of the reaction for this system is $1.83 \mathrm{eV}$. The product is the para one, which derives from the bond between the most electrophilic atom of

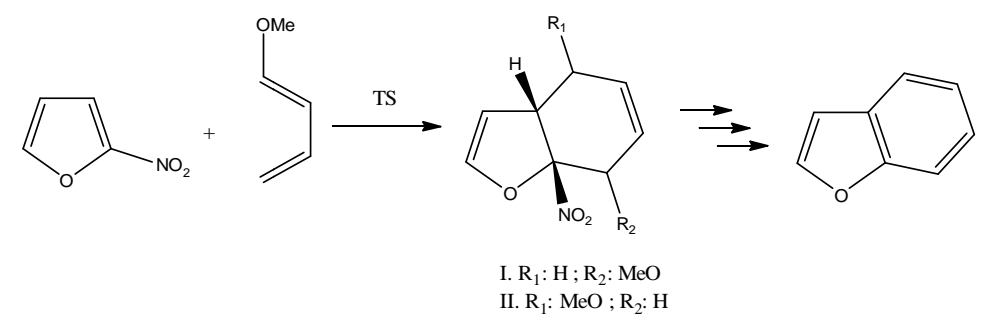

Scheme 3. Diels-Alder reaction between 2-nitrofuran and 1-methoxy-1,3-butadiene 
the dienophile $\left(\mathrm{C}_{3}\right)$ and the most nucleophilic atom of the diene $\left(\mathrm{C}_{4}\right)$. This reaction is highly asynchronous and presents two transition states $\left(\mathrm{TS}_{1}\right.$ and $\mathrm{TS}_{2}$, Fig. 6). The $\mathrm{TS}_{1}$ is associated with the bonding formation between these two reactive atoms $\left(\Delta \mathrm{r}_{T S 1}=1,24 \quad \check{A}\right)$ and the $\mathrm{TS}_{2}$ corresponds to the bonding formation between the $C_{2}$ of the dienophile and the $C_{1}$ of the diene $\left(\Delta \mathrm{r}_{T S 2}=0,90 \AA\right)$.

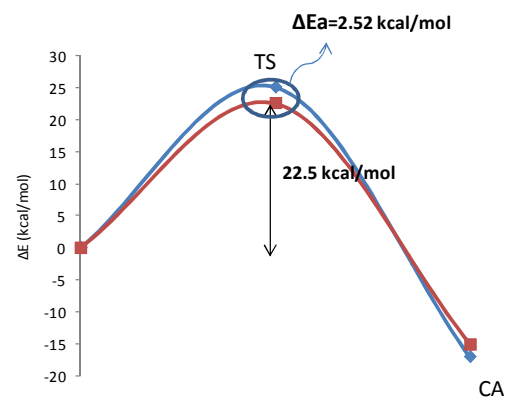

a)
The energy barrier of the $\mathrm{TS}_{1}$ is $18.95 \mathrm{kcal} / \mathrm{mol}$ and the energy of the $\mathrm{TS}_{2}$ is $16.83 \mathrm{kcal} / \mathrm{mol}$ (Fig. 7a). The energy barrier of the para cycloadduct is higher than those in which 3nitrofuran is employed as dienophile (11.31 $\mathrm{kcal} / \mathrm{mol}$ and $6.55 \mathrm{kcal} / \mathrm{mol}$ for $\mathrm{TS}_{1}$ and $\mathrm{TS}_{2}$ respectively, (Fig. $7 \mathrm{~b}$ ). Moreover, the energy of the $\mathrm{TS}_{1}$ is the determinant step of the reaction because it is higher than the one of the $\mathrm{TS}_{2}$.

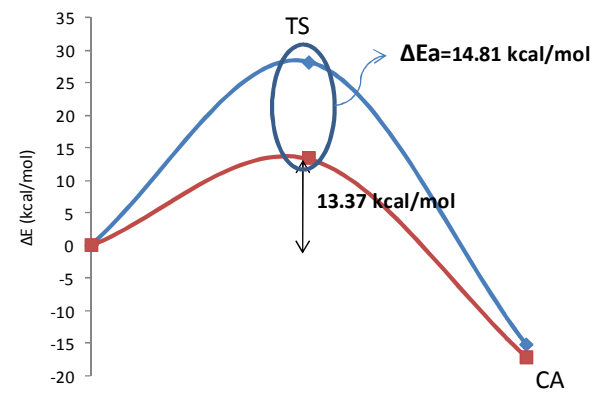

b)

Fig. 5. Reaction path of 2-nitrofuran (a) and 3-nitrofuran (b) with 1-methoxy-1,3-butadiene<smiles>C=C(/C=C/C)OC</smiles>

Scheme 4. Diels-Alder reaction between 2-nitrofuran and Danishefsky's diene

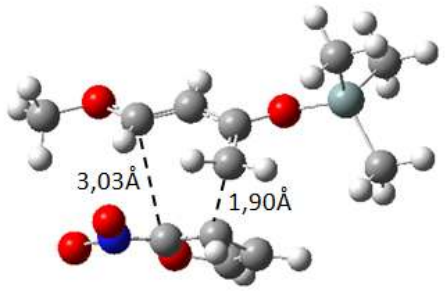

TS1

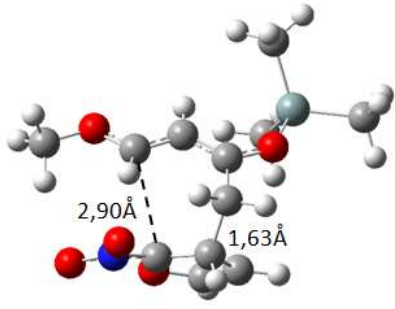

TS2

Fig. 6. Transition states for the para cycloadduct

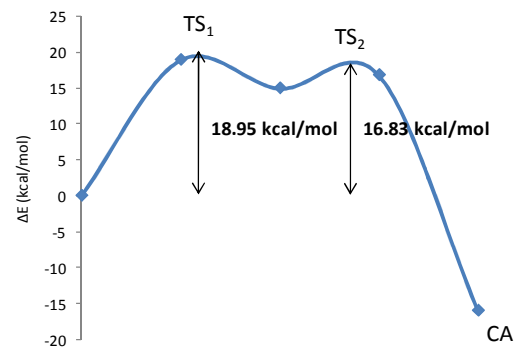

a)

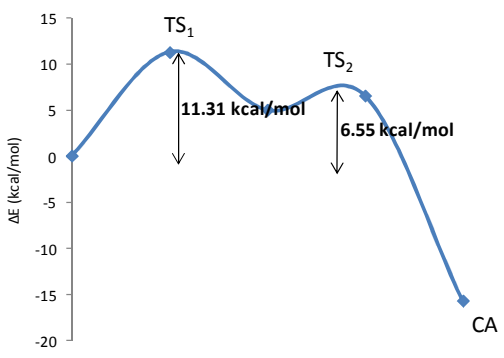

b)

Fig. 7. Reaction path of 2-nitrofuran (a) and 3-nitrofuran (b) with Danishefsky's diene 


\section{CONCLUSION}

The global electrophilicity $(\omega)$ of 2 -nitrofuran is a little higher than the one of3-nitrofuran. However, the difference of local electrophilicity $\left(\Delta \omega_{k}\right)$ between $\mathrm{C}_{2}$ and $\mathrm{C}_{3}$ is higher in the case of 3-nitrofuran, which leads to higher asynchronous TS, that can be observed in higher values of $\Delta r$.

The mechanism of these reactions is concerted and asynchronous. When isoprene and 1methoxy-1,3-butadiene are employed, only one TS is observed. However, when Danishefsky's diene is employed, two TSs are noted corresponding with each bonding formation. This is due to the higher difference of local nucleophilicity $\left(\Delta N_{k}\right)$ between $C_{1}$ and $C_{4}$ of this diene, which leads to a higher asynchronous TSs.

When isoprene is employed, the activation energies of the reactions are similar and the obtention of both isomers is equally possible. Moreover, when 1-metoxy-1,3-butadiene is employed, the mechanism suggests a preference for the ortho cycloadduct, which is more notable in case of 3-nitrofuran. However the final product is the same and the experimental determination is not possible. Finally, the reactions involving the Danishefsky's diene are completely regioselective and the product is the result of the bonding formation of the most nucleophilic atom of the diene with the most electrophilic atom of the dienophile. The $\mathrm{TS}_{1}$ is the determinant step of these reactions due to it is higher value of activation energy.

The activation energies in all the reaction are lower when 3-nitrofuran is employed as dienophile. This could be due to the higher asynchronism of this reaction in relation to 2nitrofuran, which favors the initial charge transference process between the most reactive atoms of the diene and dienophile.

\section{COMPETING INTERESTS}

Authors have declared that no competing interests exist.

\section{REFERENCES}

1. Diels O, Alder K. Syntheses in derhydro aromatis chen reihe. Justus Liebigs. Ann Chem. 1928;460:98-122.
2. (a) Carruthers W. Some modern methods of organic synthesis. (2nd edn), Cambridge University, Press Cambridge, UK; 1978. (b) Carruthers W. Cycloaddition reactions in organic synthesis. Pergamon, Oxford, UK; 1990.

3. Wenkert E, Moeller PD, Piettre SR. Fivemembered aromatic heterocycles as dienophiles in Diels-Alder reactions. Furan, pyrrole and indole. J. Am. Chem. Soc. 1988;110:7188-7194.

4. (a) Biolatto B, Kneeteman M, Paredes E, Mancini PME. Reactions of 1-Tosyl-3substituted indoles with conjugated dienes under thermal and/or high-pressure conditions. J. Org. Chem. 2001;66:39063912.

(b) Paredes E, Brasca R, Kneeteman MN, Mancini PME. A novel application of thediels-alder reaction: Nitronaphthalenes as normal electron demand dienophiles. Tetrahedron. 2007;63:3790-3799.

(c) Della RosaC, Ormachea C, Kneeteman MN, Adam C, Mancini PME. Dielsalder reactions of $\mathrm{N}$-tosylpirroles developed in protic ionic liquids. Theoretical studies using DFT methods. Tetrahedron Lett. 2011;52:6754-6757.

(d) Della Rosa CD, Ormachea CM, Sonzogni AS, Kneeteman MN, Domingo LR, Mancini PME. Polar Diels-Alder reactions developed in a protic ionic liquid: 3-Nitroindole as dienophile. Theoretical Studies Using DFT Methods. Lett. Org. Chem. 2012;9:691-695.

(e) Della Rosa C, Kneeteman M, Mancini $P$. Comparison of the reactivity between 2and 3-nitropyrroles in cycloaddition reactions. A simple indole synthesis. Tetrahedron Lett. 2007;48:1435-1438. (f) Della Rosa C, Kneeteman M, Mancini P. 2-Nitrofurans as dienophiles in Diels-Alder reactions. Tetrahedron Letters. 2005;46: 8711-8714.

5. Hehre WJ, Radom L, Schleyer PvR, Pople $\mathrm{JA}$. Ab initio molecular orbital theory. Wiley: New York; 1986.

6. Domingo LR, Saez JA. Understanding the mechanism of polar Diels-Alder reactions. Organic and Biomolecular Chemistry. 2009;7:3576.

7. (a) Domingo LR, Saéz JA, Zaragozá RJ, Arno M. understanding the participation of quadricyclane as nucleophile in polar 2 sigma +2 sigma +2 pi cycloadditions 
toward electrophilic pi molecules. Journal of Organic Chemistry. 2008;73:8791-8799. (b) Jaramillo P, Domingo LR, Chamorro E, Pérez P. A further exploration of a nucleophilicity index based on the gas phase ionization potentials. Journal of Molecular Structure-Theochem. 2008; 865:68-72.

8. (a) Check CE, Gilbert TM. Progressive systematic underestimation of reaction energies by the B3LYP model as the number of $\mathrm{C}-\mathrm{C}$ bonds increases: Why organic chemists should use multiple DFT models for calculations involving polycarbon hydrocarbons. J. Org. Chem. 2005;70:9828-9834.

(b) Jones GO, Guner VA, Houk KN. Diels-alder reactions of cyclopentadiene and 9,10-dimethylanthracene with cyanoalkenes: The performance of density functional theory and Hartree-Fock calculations for the prediction of substituent effects. J. Phys. Chem. A. 2006;110:1216-1224.

(c) Griffith GA, Hillier IH, Moralee AC, Percy JM, Roig R, Vicent MK. Interplay of structure and reactivity in a most un usual furan Diels-Alder reaction. J. Am. Chem. Soc. 2006;128:13130-13141.

(d) Ríos-Gutiérrez M, Pérez P, Domingo LR. A bonding evolution theory study of the mechanism of [3+2] cycloaddition reactions of nitrones with electron-deficient ethylenes. RSC Adv. 2015;5:58464-58477.

9. Zhao $Y$, Truhlar DG. Hybrid meta density functional theory methods for thermos chemistry, thermos chemical kinetics, and noncovalent interactions: TheMPW1B95 and MPWB1K models and comparative assessments for hydrogen bonding and van der waals interactions. J. Phys. Chem. A. 2004;108:6908-6918.

10. (a) Reed AE, Weinstock RB, Weinhold F. Natural population analysis. J. Chem. Phys. 1985;83:735-746.

(b) Reed AE, Curtiss LA, Weinhold F. Intermolecular interactions from a natural bond orbital, donor-acceptor viewpoint. Chem. Rev. 1988;88:899-926.

11. Bini R, Chiappe C, Mestre VL, Pomelli CS, Welton T. A theoretical study of the solvent effect on Diels-Alder reaction in room temperature ionic liquids using supramolecular approach. Theor. Chem. Acc. 2009;123:347-352.
12. Cainelli $M$, Ormachea $C$, Kneeteman $M$, Mancini P. A theoretical study of the DielsAlder reaction between 3-nitrofuran and different dienes developed in ionic liquids. International Journal of Pure and Applied Chemistry (IJPAC). 2016;12:1-10.

13. Gaussian 09, Revision E.01. Frisch MJ, Trucks GW, Schlegel HB, Scuseria GE, Robb MA, et al. Gaussian, Inc., Wallingford CT; 2009.

14. (a) Parr RG, von Szentpaly L, Liu S. Electrophilicity index. J. Am. Chem. Soc. 1999;121:1922-1924.

(b) Parr RG, Pearson RG. Absolute hardness: Companion parameter to absolute electronegativity. J. Am. Chem. Soc. 1983;105:7512-7516.

(c) Parr RG, Yang W. Density functional theory of atoms and molecules. Oxford University Press: New York; 1989.

15. (a) Lee C, Yang W, Parr RG. Development of the colle-salvetti correlation-energy formula into a functional of the electron density. Phys. Rev. B: Condens. Matter Mater. Phys. 1988;37:785-789.

(b) Becke AD. Density functional thermochemistry. III. The role of exact exchange. J. Chem. Phys. 1993;98:56485652.

16. Morales-Bayuelo A, Vivas-Reyes RU. Understanding the polar character trend in a series of Diels-Alder reactions using molecular quantum similarity and chemical reactivity descriptors. Journal of Quantum Chemistry. 2014;Article ID 239845.

17. Hehre WJ, Radom L, Schleyer PVR, Pople $\mathrm{JA}$. Ab initio molecular orbital theory. Wiley: New York; 1986.

18. Gonzáles C, Schlegel HB. Reaction path following in mass-weighted internal coordinates. J. Phys. Chem. 1990;94: 5523.

19. Kohn W, Sham LJ. Self-consistent equations including exchange and correlation effects. Phys. Rev. 1965; 140:1133-1138.

20. (a) Domingo LR, Chamorro E, Pérez P. Understanding the reactivity of captodative ethylene's in polar cycloaddition reactions. A theoretical study. J. Org. Chem. 2008; 73:4615-4624.

(b) Domingo LR, Pérez P. The nucleophilicity $N$ index inorganic chemistry. Org. Biomol. Chem. 2011; 9:7168-7175. 
21. Fukui $\mathrm{K}$, Formulation of the reaction coordinate. J. Phys. Chem. 1970;74:41614163.

22. Domingo LR, Aurell MJ, Pérez $P$, Contreras R. Quantitative characterization of the global electrophilicity power of common dienedienophile pairs in DielsAlder reactions. Tetrahedron. 2002;58: 4417-4423.

(c) 2016 Cainelli et al.; This is an Open Access article distributed under the terms of the Creative Commons Attribution License (http://creativecommons.org/licenses/by/4.0), which permits unrestricted use, distribution, and reproduction in any medium, provided the original work is properly cited.

Peer-review history:

The peer review history for this paper can be accessed here: http://sciencedomain.org/review-history/17020 